\title{
Endoscopic Hemostatic Treatment of Gastric Varices during Pregnancy by Injection of Histoacryl
}

\author{
Nora Bousfiha ${ }^{*}$, Najoua Bousfiha², Chahrazad Bouchikhi², Abdelaziz Banani², \\ Adil Ibrahimi ${ }^{1}$, Nourdin Aqodad ${ }^{1}$ \\ ${ }^{1}$ Service d'hépato-gastro-entérologie, CHU Hassan II, Fès, Maroc \\ ${ }^{2}$ Service de gynécologie-obstétrique 1, CHU Hassan II, Fès, Maroc \\ Email: ${ }^{*}$ bousfiha nora@hotmail.com
}

Received 5 February 2014; revised 10 March 2014; accepted 18 March 2014

Copyright (C) 2014 by authors and Scientific Research Publishing Inc.

This work is licensed under the Creative Commons Attribution International License (CC BY). http://creativecommons.org/licenses/by/4.0/

(c) (i) Open Access

\begin{abstract}
The occurrence of pregnancy is relatively rare in patients with portal hypertension, and has been reported as clinical cases. However, few studies have evaluated the effectiveness of injecting histoacryl during pregnancy. The choice of treatment for varicose bleeding during pregnancy has been described in the literature based on the elastic ligature. We report the second case, to our knowledge, of treatment of bleeding gastric varices by injection of histoacryl with good maternal and fetal development.
\end{abstract}

\section{Keywords}

Gastric Varices; Pregnancy; Hystoacryl

\section{Introduction}

The pregnancy occuring during portal hypertension, regardless of its etiology, is relatively rare due to subfertility [1]-[3]. However, serious complications can occur both in the fetal and maternal level, mainly related to upper gastrointestinal bleeding caused by ruptured esophageal varices and/or gastric varices preexisting. The management of these patients should be multidisciplinary because of maternal-fetal risk. Hemostatic treatment of oesophageal varices during pregnancy is mainly based on endoscopic ligation [4] [5]. However, the injection of fibrin glue endoscopically during pregnancy has been rarely reported. We report a case of a pregnant patient ad-

${ }^{*}$ Corresponding author.

How to cite this paper: Bousfiha, N., Bousfiha, N., Bouchikhi, C., Banani, A., Ibrahimi, A. and Aqodad, N. (2014) Endoscopic Hemostatic Treatment of Gastric Varices during Pregnancy by Injection of Histoacryl. Open Journal of Gastroenterology, 4, 149-151. http://dx.doi.org/10.4236/ojgas.2014.44022 
mitted to the gastroenterology service for management of upper gastrointestinal bleeding from ruptured gastric varices and treated by injecting histoacryl.

\section{Case Report}

A 29-year-old patient, 5 G 4 P, pregnant at her 14 weeks of amenorrhea, has been admitted in the service of gastroenterology for the treatment of a high digestive bleeding. The patient had presented two weeks before its admission several average abundance episodes of hematemesis associated to mélénas and to anemic syndrome. The general examination had pointed a patient GSC $=15$, non icterus, without signs of HTP and the rectal touch indicated the presence of méléna. In complementary, the gynéco-obstetric examination had found an evolutionary pregnancy. The results of the biological balance sheet assessed a pancytopénie with a haemoglobin $=4,4$ $\mathrm{g} / \mathrm{dl}, \mathrm{VGM}=86, \mathrm{CCMH}=32$, plaques = 83,000, GB = 3900, TP = 100/, GOT: 28, GPT: 30.

An endoscopy was performed 24 hours after the bleeding period and had objectified stage I of esophageal varices with some red signs associated with two large varices with red signs in cardia, the patient had received an injection of a chemical glue 1cc at the gastric varices without maternal neither fetal incident. An abdominopelvic ultrasound was performed and showed signs of portal hypertension and signs of chronic liver disease with progressive singleton pregnancy. The evolution was marked by a smooth pregnancy and delivery at term vaginally of a newborn male, birth weight $3000 \mathrm{~g}$, APGAR 10/10 with good psychomotor development. Nine months later, the patient presented bleeding. An upper endoscopy showed a varicose vein in the cardia, which was treated by histoacryl of injection (Figures 1 and 2).

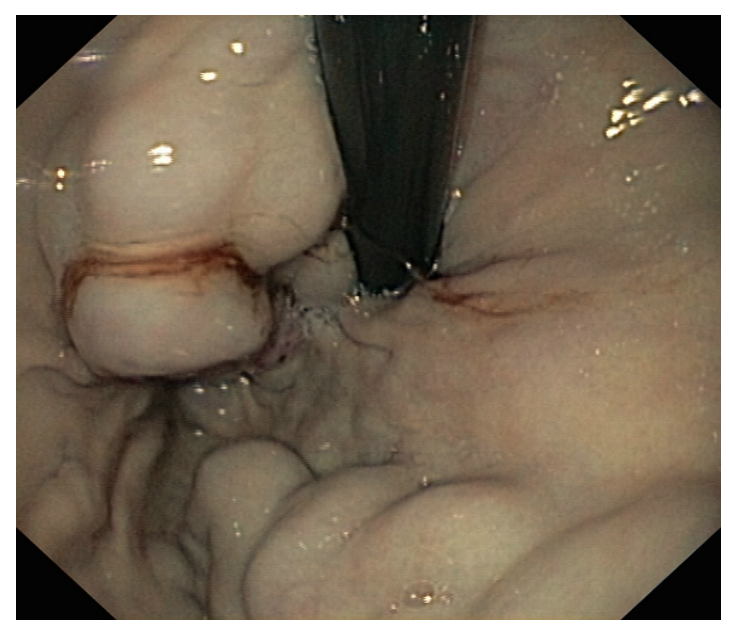

Figure 1. Gastric varices.

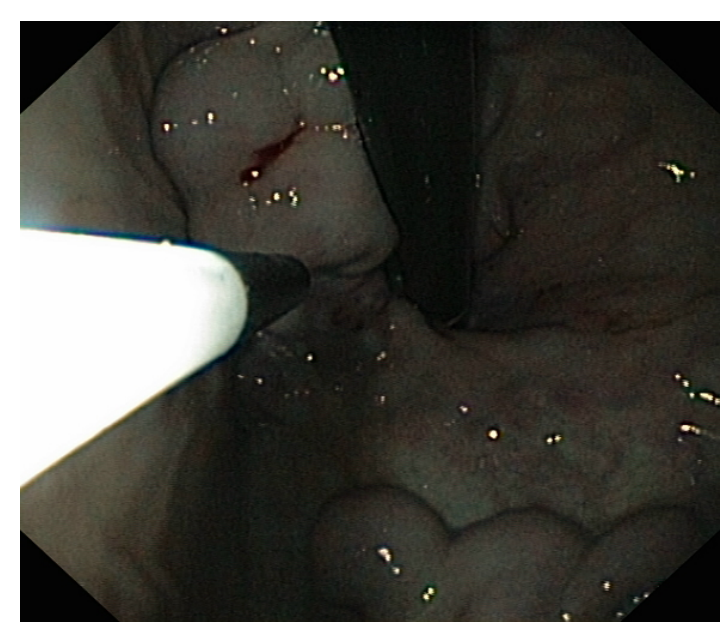

Figure 2. Injection of histoacryl. 


\section{Discussion}

Portal hypertension occurring during pregnancy is a problem of therapeutic management because of the maternal and fetal complications that could lead to [4] [6]. Hemorrhage by rupture of varicose veins occur mainly during the second and third quarter related to the increased blood flow and fetal volume responsible for compression of the inferior vena cava by the gravid uterus [6]-[8]. Maternal mortality is 400 times that of a normal pregnancy when portal hypertension is complicated by hemorrhage [6]. The vaginal delivery analgesia should be preferred to cesarean whose particulars shall be obstetrical order [6]. The treatment of esophageal varices during pregnancy is mainly based on ligation [5]. However, only one case of gastric varices treatment by chemical glue has been described in the literature. This case was about a woman aged of 26 years old with a history of upper gastrointestinal bleeding in whom an abdominal ultrasound performed at 24 weeks of pregnancy revealed the presence of portal hypertension on caverrnome door. Endoscopy had objectified a varicose vein in cardia treated by histoacryl associated with esophageal variceal three cords were ligated injection. Endoscopic control showed the irradiation of gastric varices [8].

Our case confirms the safety of chemical glue given the favorable pregnancy outcome in our patient.

\section{Conclusion}

The treatment of gastric varices during pregnancy by injection of chemical glue seems to be effective. However, it is necessary to perform more studies to prove its safety on the maternal and fetal levels.

\section{References}

[1] Russel, M.A. and Craigo, S.D. (1998) Cirrhosis and Portal Hypertension in Pregnancy. Seminars in Perinatology, 22, 156-165. http://dx.doi.org/10.1016/S0146-0005(98)80048-7

[2] Cheng, Y.S. (1977) Pregnancy in Liver Cirrhosis. American Journal of Obstetrics \& Gynecology, 128, $812-822$.

[3] Kochhar, R., Kumar, S., Goel, R.S., Sriram, P.V., Goenca, M.K. and Sing, K. (1999) Pregnancy Is Outcome in Patients with No Cirrhotic Portal Hypertension. Digestive Diseases Sciences, 44, 1356-1361. http://dx.doi.org/10.1023/A:1026687315590

[4] Jennifer, T., Bijal, S., et al. Pregnancy and Cirrhosis and/or Portal Hypertension.

[5] Starkel, P., Horsmans, Y. and Geubel, A. (1998) Endoscopic Band Ligation: A Safe Technique to Control Bleeding Esophageal Varices in Pregnancy. Gastro Intestinal Endoscopy, 48, 212-214. http://dx.doi.org/10.1016/S0016-5107(98)70169-5

[6] Dalteroche, L., Perarenau, J.-M., Perrotin, F. and Bacq, Y., et al. Grossesse et hypertension portale.

[7] Misra, S. and Sanyal, A.J. (1999) Pregnancy in a Patient with Portale Hypertension. Clinical Liver Disease, 3, $147-162$. http://dx.doi.org/10.1016/S1089-3261(05)70059-3

[8] Radha, K., Dhiman, M.D., Rakesh Biswas, M.D., Neelam Aggarwal, M.D., Harjit Sawhney, M.D. and Yogesh Chawla, M.D., et al. Management of Variceal Bleeding in Pregnancy with Endoscopic Variceal Ligation and N-butyl-2-cyanoacrylate: Report of Three Cases. 